\title{
A tribute to Leo C Vining
}

The Journal of Antibiotics (2013) 66, 359-360; doi:10.1038/ja.2013.47

$\mathrm{O}$ ne of the greatest chemical biologists dealing with antibiotic production by streptomycetes was Leo Charles Vining. Born on a farm in Whangareri, New Zealand in 1925, he first became a chemist and then later a microbiologist. During World War II, Leo joined the New Zealand Navy and traveled to Canada to train as a pilot. After the war, he returned to New Zealand and enrolled in the University of Aukland. After receiving his Bachelor of Science degree in Chemistry there in 1948 and then a Master of Science degree in Chemistry in 1949, Leo moved on to the Cambridge University in England where he successfully completed his Ph.D. studies in Organic Chemistry in 1952. He then moved on to research appointments at the Kiel University in Germany, and later to the Rutgers University in the United States of America. One might guess that Leo's love of the streptomycetes began at the Rutgers University where Selman Waksman and his students, such as Albert Schatz, Boyd Woodruff and Hubert Lechevalier, had become famous for their discoveries of streptomycin and other antibiotics produced by streptomycetes.

His appreciation of microbes came mostly from the fascination of their chemistries and seemingly boundless innovative chemical structures assembled by a process he considered 'inventive evolution'. He very quickly realized the great potential of using a combined approach of chemistry and biology in his pursuit to better appreciate these organisms and the chemical crafting of their elaborate structures. These explorations were important to Leo, first in his attempts to chemically synthesize actinomycin, devise techniques to isolate this compound in purity, and further, to reveal the monomeric building blocks used in actinomycin assembly. Continuing these endeavors after working at Rutgers as an Instructor and instilling a chemical biology approach to antibiotics while there, Leo brought this style to the National Research Council of Canada where he opened his laboratory (adequately named the Chemical Biology Laboratory) at the Prairie Research Laboratory in 1955, and then later at the Atlantic Research Laboratory (ARL) in 1962. At ARL, Leo carried out pioneering work on the biosynthesis of microbial metabolites, such as the fungal tropolone sepedonin. In addition to his teaching a course on Applied Microbiology, he worked in the laboratory with his students including post-doctorals. In 1971, Leo became Professor of Biology at the University of Dalhousie in Halifax and began his work on antibiotics that made Dalhousie University famous in microbiology and natural product chemistry throughout the world. His research dealt with polyketide folding, antibiotic resistance, jadomycin biosynthesis and its genetics and regulation, nutritional control of chloramphenicol biosynthesis, chemical characterization of the viridomycins produced by Streptomyces griseus, metabolic control of cephamycin C biosynthesis in Streptomyces clavuligerus, biosynthesis of hydroxyl-4-norvaline (an antifungal agent produced by Streptomyces akiyoshensis) and the molecular biology of secondary metabolism. Leo was an extraordinary teacher and was respected by his students, many of whom also became famous in the field of industrial microbiology.

Leo published 283 papers within the areas of antibiotics and natural products, which were well noted for their variety of chemical biological approaches taken to explore microbial chemistry and biosynthesis. He was a great writer and presented his thoughts in a clear manner. He was the President of the Nova Scotian Institute of Science in 1980-1981. He contributed greatly to the Canadian Society of Microbiology (CSM) and to its publication, the Canadian Journal of Microbiology. He chaired the Microbial Physiology section and the Awards committee, and was the President of the CSM from 1992 to 1993. His recognition was extensive, including the Merck Sharp \& Dohme award in Bio-Organic Chemistry, the Labatt Prize from the Chemical Institute of Canada, the Harrison Prize in Microbiology from the Royal Society of Canada (RCM), Fellowship in the RCM, the CSM award, the Charles Thom Award of the Society for Industrial Microbiology and a Killiam Research Professorship at Dalhousie University from 1986 to 1990. He was also Honorary Professor of Shenyang Pharmaceutical University in China. There is no doubt that Leo was a great natural product scientist, both as a chemist and microbiologist.

The students of Leo loved working with him. He taught them about science, integrity and life. Leo was a great humanitarian and inspired his students to great heights. He encouraged new ideas from students and embraced differences. He enjoyed cultural diversity and his students came from all over the world. Often, he would meet a new student at the airport, take the student out for a meal, and invite the student to stay at his home for several days. Leo had an 'opendoor' policy when it came to student's questions and discussions. His kindness to students was outstanding and was extremely surprising to students from around the world who thought professors were authorative and formal. He made all of his students feel valuable and, as a result, they were very creative and successful. He created an environment of trust, respect and sincere interest in the well-being of his students. He loved working at the bench and discussing results with his group. His eyes would light up and twinkle when he observed good experimental results, and, on the other hand, when results did not make sense, he would quietly and patiently review the data and engage in discussions with the students about figuring a way forward. Leo entertained his students on Friday night at the 'Bio-Bar' in the Biology Lounge. He not only entertained his students at dinners in restaurants, but also in his home. At home, he had many parties which featured microbially-produced foods and liquids. The liquids, 
of course, included beer which had been made by his laboratory group. Leo had a unique and compassionate way of teaching microbiology and chemistry. His books titled 'Genetics and Biochemistry of Antibiotic Production' and 'Biochemistry and Genetic Regulation of Commercially Important Antibiotics' were great inspirations to his students.

Leo was rare for his many scientific qualities which are well recognized; others were less known but revered by those who worked with him. He had a strong ability for direct recall of a full catalog of natural product chemical structures, but these abilities would only be shown if asked and never to impress. His way was certainly by example, and although quiet, he was quick to correct false information or to decisively reveal improper reasoning and logic both from a biological and chemical perspective. He ran a laboratory that was open to individuals of all backgrounds and individual styles, but was also methodological and well-organized (filled with card-based indexing of strains, chemicals and analytical parts). By the later part of his career, his research had increasingly evolved toward a biological path, as many of the unresolved questions seemingly dealt with the unraveling of biosynthetic gene clusters and their regulation. Not wanting to disengage from organic chemistry, he maintained an elaborate laboratory comprised of glassware accumulated over a long career and, although that is now gone, his memory and a red maple on the Dalhousie campus still stand as testaments to a kind and thoughtful mentor and a superb student of the chemical biology of natural products.

Nathan A Magarvey ${ }^{1,2}$ and Arnold L Demain ${ }^{3}$ ${ }^{1}$ Department of Biochemistry and Biomedical Sciences, M. G. De Groote Institute for Infectious Disease Research, McMaster University, Hamilton, Ontario, Canada; ${ }^{2}$ Department of Chemistry and Chemical Biology, M. G. De Groote Institute for Infectious Disease Research, McMaster University, Hamilton, Ontario, Canada and ${ }^{3}$ Research Institute for Scientists Emeriti (R.I.S.E.), Drew University, Madison, NJ, USA E-mail: ademain@drew.edu 